\title{
Experimental investigation of the cascadability of a cross-gain modulation wavelength converter
}

\section{Zheng, Xueyan; Liu, Fenghai; Kloch, Allan}

\section{Published in:}

I E E E Photonics Technology Letters

Link to article, DOI:

$10.1109 / 68.826911$

Publication date:

2000

Document Version

Publisher's PDF, also known as Version of record

Link back to DTU Orbit

Citation (APA):

Zheng, X., Liu, F., \& Kloch, A. (2000). Experimental investigation of the cascadability of a cross-gain modulation wavelength converter. I E E E Photonics Technology Letters, 12(3), 272-274. https://doi.org/10.1109/68.826911

\section{General rights}

Copyright and moral rights for the publications made accessible in the public portal are retained by the authors and/or other copyright owners and it is a condition of accessing publications that users recognise and abide by the legal requirements associated with these rights.

- Users may download and print one copy of any publication from the public portal for the purpose of private study or research.

- You may not further distribute the material or use it for any profit-making activity or commercial gain

- You may freely distribute the URL identifying the publication in the public portal 


\title{
Experimental Investigation of the Cascadability of a Cross-Gain Modulation Wavelength Converter
}

\author{
Xueyan Zheng, Fenghai Liu, and Allan Kloch
}

\begin{abstract}
The cascading characteristics of a wavelength converter based on cross-gain modulation (XGM) are studied experimentally using a recirculating loop at $10 \mathrm{~Gb} / \mathrm{s}$. The maximum cascaded number of the wavelength converter converting the signal to the same wavelength is improved from five to eight by adding a fiber grating-based optical add-drop multiplexer after the semiconductor optical amplifier (SOA) to enhance the high-frequency response of the wavelength converter. However, the low-frequency degradation of the signal together with amplified spontaneous emission (ASE) noise and jitter accumulation finally limits the wavelength converter to be cascaded for more times.
\end{abstract}

Index Terms-Cascadability, cross-gain modulation (XGM), semiconductor optical amplifier (SOA), wavelength conversion.

\section{INTRODUCTION}

A LL-OPTICAL wavelength converters (AOWC's) will be key components in future broad-band wavelength-division-multiplexed (WDM) optical networks. Among several AOWC's already demonstrated, the AOWC based on cross-gain modulation (XGM) in a semiconductor optical amplifier (SOA) is the simplest to realize and capable of converting the input signal to the same wavelength, which is favorable in all-optical networks [1], [2]. An important issue for the AOWC to be used in the WDM networks is its cascadability. However, up to now, only a few theoretical results have been reported, which do not consider the pattern effect [3], [4]. Actually, in practical systems, the cascadability of this kind of AOWC is limited seriously by the insufficient high-frequency response of the AOWC, which is caused by the slow gain recovery time of the SOA when it works at high bit rate. Recently, it has been reported that the frequency response of the AOWC can be improved by adding a fiber grating after the SOA, which reshapes the chirped converted signal [5].

In this paper, for the first time, the cascadability of the XGM-AOWC is studied experimentally using a recirculating loop setup at $10 \mathrm{~Gb} / \mathrm{s}$. The experiment shows that the maximum number of cascaded AOWC's converting the signal to the same wavelength is 5 mainly due to the degradation of the high-frequency components of the signal. By adding a Mach-Zehnder optical add-drop multiplexer (OADM) based on fiber gratings after the SOA, the maximum cascading round-trips in the loop is increased to eight due to the improved high-frequency response in the AOWC. However, the inherent low-frequency degradation in the cascaded signal together with

Manuscript received September 30, 1999; revised November 16, 1999. The authors are with the Research Center COM, Technical University of Denmark, Lyngby DK-2800, Denmark (e-mail: zx@com.dtu.dk).

Publisher Item Identifier S 1041-1135(00)01993-5.

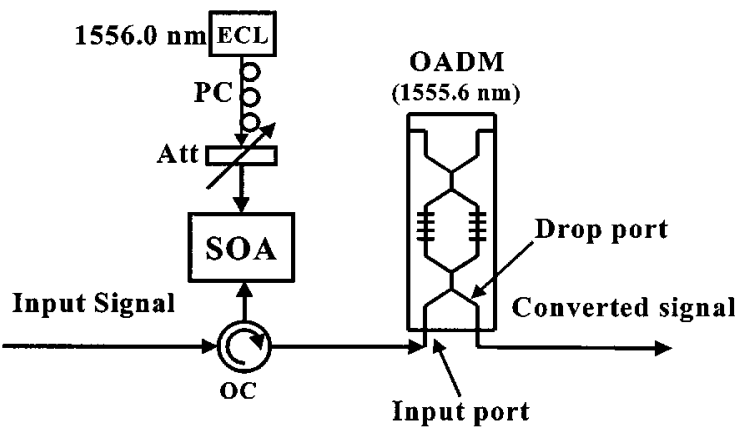

(a)

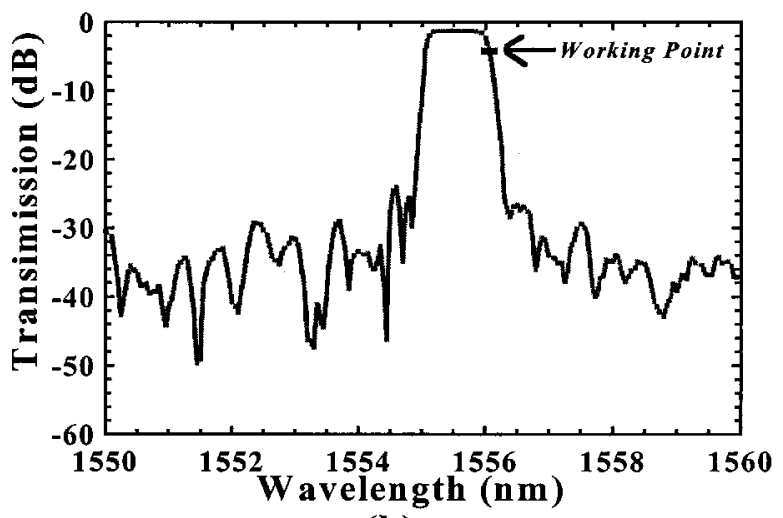

(b)

Fig. 1. (a) Structure of the AOWC. (b) In-drop transfer function of the OADM. PC: Polarization controller. Att: Tunable attenuator. OC: Optical circulator. ECL: External cavity laser.

the accumulation of ASE noise and jitter limits the AOWC to be cascaded for more times.

\section{EXPERIMENTAL SETUP}

In the experiment, the AOWC performs the conversion to the same wavelength. The structure of the counterpropagating AOWC is shown in Fig. 1(a). The CW light is provided by an external cavity laser (ECL) and the power into the SOA is $-1 \mathrm{dBm}$ after a polarization controller and an attenuator. The input signal with a power of $+8 \mathrm{dBm}$ is launched into the SOA through an optical circulator (OC). The converted signal from the SOA comes into the OADM from the input port and comes out from the drop port. The OADM with a center wavelength of $1555.6 \mathrm{~nm}$ and a $3-\mathrm{dB}$ bandwidth of $1 \mathrm{~nm}$ is used to reshape the converted signal when the wavelength of the converted signal is at the red side of the in-drop transfer function [6], which is $1556.0 \mathrm{~nm}$ in the experiment. The in-drop transfer function of 


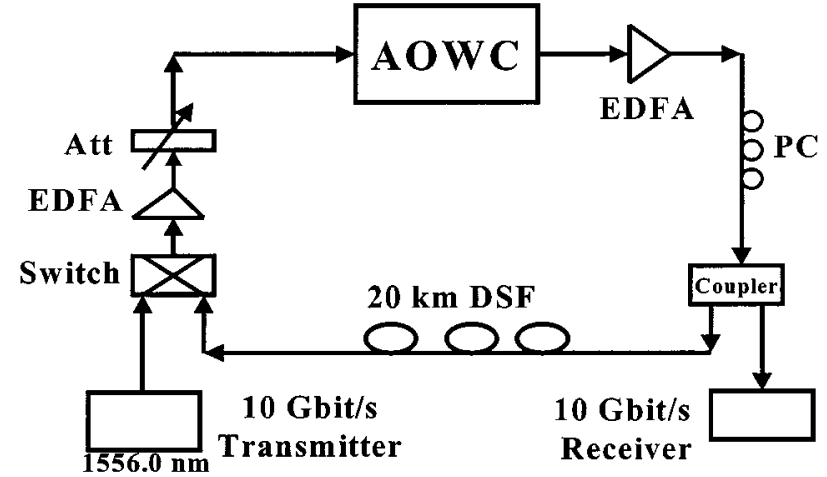

Fig. 2. Loop experimental setup. PC: Polarization controller. Att: Tunable attenuator. DSF: Dispersion-shifted fiber.

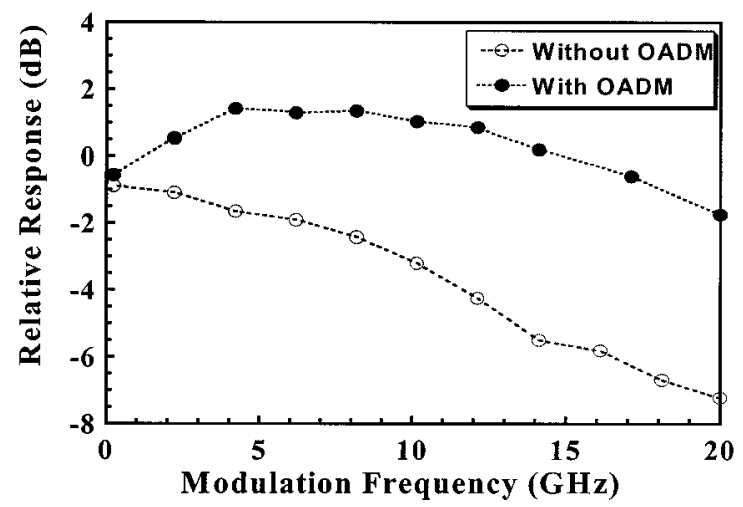

Fig. 3. Small signal bandwidths of the AOWC without and with the OADM.

the OADM and the working point in the experiment are shown in Fig. 1(b). The cascadabilities of the AOWC both with and without the OADM are measured in the loop experiment. The AOWC without the OADM actually means that the wavelength of the continuous-wave (CW) light is located at the center of the OADM in order to keep the same ASE level as when the OADM is used to reshape the converted signal. The SOA used in the experiment has a chip length of $1250 \mu \mathrm{m}$, and the fiber-to-fiber gain is $20 \mathrm{~dB}$ at a bias current of $250 \mathrm{~mA}$, which is used in our experiment. The reflection from the facets of the SOA is smaller than $-26 \mathrm{~dB}$. The loop setup used in the experiment is shown in Fig. 2. An externally modulated $10 \mathrm{~Gb} / \mathrm{s}$ [pseudorandom binary signal (PRBS) $2^{31}-1$ ] tuneable transmitter provides the input signal to the AOWC in the loop, as shown in Fig. 2. The power of input signal and the $\mathrm{CW}$ light to the AOWC are kept constant for every round-trip. The polarization controllers in the setup are used to keep the interference between the converted signal and the reflected signal be minimum, so, the impact of crosstalk from the reflection can be neglected. Only $20 \mathrm{~km}$ of dispersion shifted fiber is used in the loop, so the dispersion can be neglected. The signal is coupled out via a 10-dB coupler and launched into a $10-\mathrm{Gb} / \mathrm{s}$ receiver.

\section{RESULTS AND DISCUSSIONS}

Fig. 3 shows the relative responses of the AOWC versus the modulation frequency at $1556 . \mathrm{nm}$ with and without the OADM. Owing to the carrier density variation in the SOA, the converted signal from the SOA has blue chirp on the rising edge and red

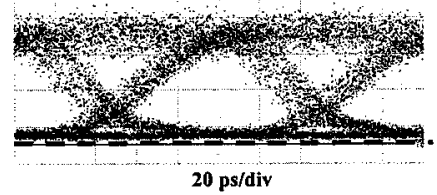

(a)

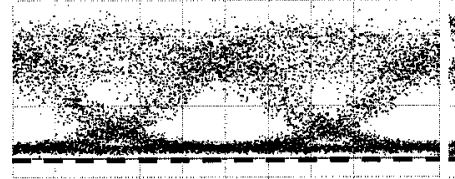

$20 \mathrm{ps} / \mathrm{div}$

(c)

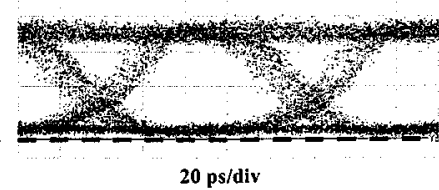

(b)

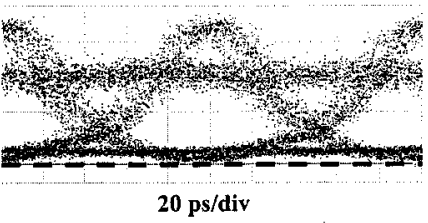

(d)
Fig. 4. The eye diagrams of the converted signal (a), (c) without and (b), (d) with the OADM after the second and fifth round-trips in the loop experiment, respectively.

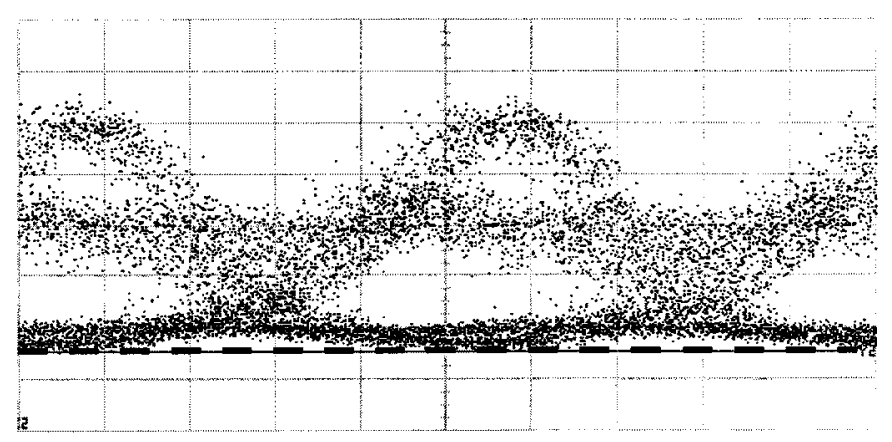

Fig. 5. The eye diagrams of the converted signal after the tenth round-trips.

chirp on the falling edges [1]. After the OADM, the falling edge of the converted signal with red chirp is suppressed by the steep edge of the transfer function of the OADM, and consequently the response of the AOWC at high frequency is improved [5]. It can be seen from Fig. 3 that the high-frequency response is improved significantly and the $3-\mathrm{dB}$ bandwidth is larger than $20 \mathrm{GHz}$ when the OADM is added. Fig. 4(a) and (b) shows the optical eye diagrams after the second conversion without and with the OADM, respectively. The dashed lines indicate the zero optical power level. It can be seen from Fig. 4(a) and (b) that the rising and falling edges are improved by using the OADM due to the improved response bandwidth. Fig. 4(c) and (d) shows the eye diagrams after the fifth round-trip in the loop without and with the OADM, respectively. From Fig. 4(c), we can see that the insufficient response of the high-frequency components (single "mark" and "space" bits) in the AOWC without the OADM is the most important factor limiting the cascadability. From Fig. 4(d), it can be seen that the degradation of low-frequency components (long row of "mark" and "space" bits) in the converted signal becomes the limiting factor since there is no chirp on the low-frequency components, the amplitude cannot be changed by the OADM. Fig. 5 shows the optical eye diagram of the converted signal after the tenth round-trip. It can be seen from Fig. 5 that the degradation of low-frequency components together with the accumulation of ASE noise and jitter caused by the AOWC limits the AOWC to be cascaded for more round-trips.

The cascadability can be improved from five to eight roundtrips without an error floor at a bit-error rate (BER) of $10^{-9}$ 


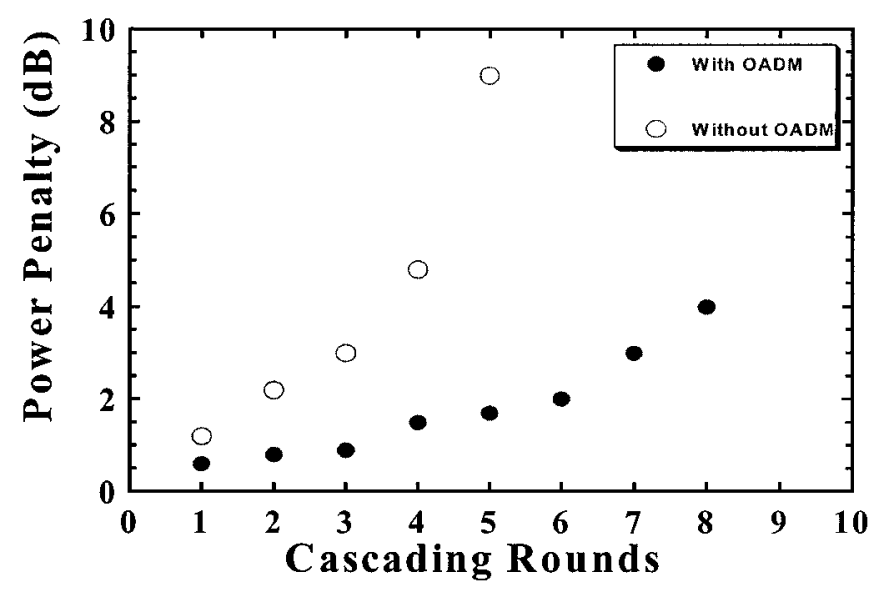

Fig. 6. Power penalty of the converted signal versus the cascading round-trips in the loop.

by adding the OADM after the SOA. Fig. 6 shows the power penalty of the converted signal with and without the OADM, respectively, as a function of different round-trips in the loop. It should be pointed out that there is a tradeoff among the parameters, like extinction ratio (ER), pattern effect, jitter and noise accumulation, all the parameters are optimized in our experiment. The power ratio between the signal and $\mathrm{CW}$ light used in the experiment corresponds to the theoretical predication in [4], which assures a small amount of jitter and a high extinction ratio (ER). However, the maximum number of cascaded AOWC's in the experiment is less than the theoretical predication in [4]. This is because the SOA used in the experiment is shorter than that in [4], the ER degradation is more severe. Furthermore, the ASE noise is not considered in [4]. It should also be stressed that using a loop configuration to test cascadability of the XGM-AOWC prevents any individual adjustments of the operation conditions for the cascaded AOWC's. So it is expected that the cascadability of the AOWC with the OADM can be improved further if a straight-line transmission or a longer SOA is used. Furthermore, it is expected that the cascadability of the XGM-AOWC converting to both longer wavelength and shorter wavelength can be improved by adding the OADM with a corresponding center wavelength.

\section{CONCLUSION}

The cascadability of the XGM-AOWC converting the signal to the same wavelength is studied experimentally at $10 \mathrm{~Gb} / \mathrm{s}$ using a loop setup. The poor high-frequency response of the AOWC limits it to be cascaded only five times in the loop experiment. By adding an OADM after the SOA, the maximum number of cascaded AOWC reaches eight due to the improved high-frequency response. However, the degradation of low-frequency components in the converted signal together with the accumulation of ASE and jitter become the most important limiting factors in the cascading experiment. It is expected that the cascadability of the AOWC with the OADM can be improved further if a straight-line transmission or a longer SOA is used.

\section{REFERENCES}

[1] T. Durhuus, B. Mikkelsen, C. Joergensen, S. Danielsen, and K. Stubkjaer, "All-optical wavelength conversion by semiconductor optical amplifiers," J. Lightwave Technol., vol. 14, pp. 942-953, June 1996.

[2] R. J. S. Pedersen, B. F. Jorgensen, B. Mikkelsen, M. Nissov, K. E. Stubkjaer, K. Wunstel, K. Daub, E. Lach, G. Lsube, W. Idler, M. Schilling, P. Doussiere, and F. Pommerau, "Cascadability of a nonblocking WDM crossconnect based on all-optical wavelength converters for routing and wavelength slot interchanging," Electron. Lett., vol. 30, no. 19, pp. 1647-1648, Sept. 1997.

[3] K. Oberman, D. Breuer, and K. Petermann, "Theoretical estimation of the cascadability of wavelength converters based on cross-gain modulation in semiconductor optical amplifiers," in Proc. CLEO'98, OSA Tech. Dig. Series, vol. 6, 1998, pp. 388-389.

[4] A. Kloch and K. E. Stubkjaer, "Accumulation of jitter in cascaded wavelength converters based on semiconductor optical amplifiers," in Proc. OFC'99, FB4-1, 1999, pp. 33-35.

[5] H.-Y. Yu, D. Mahgerefteh, P.-S. Cho, and J. Goldhar, "Optimization of the frequency response of a semiconductor optical amplifier wavelength converter using a fiber Bragg grating," J. Lightwave Technol., vol. 17, pp. 308-313, Feb. 1999.

[6] X. Zheng, F. Liu, A. Clausen, and A. Buxens, "High performance wavelength converter based on semiconductor optical amplifier and Mach-Zehnder interferometer optical add/drop multiplexer," in Proc. 10th Optic. Amplifiers Their Appl., OSA Tech. Dig., 1999, pp. 132-134. 